\title{
SHARP COEFFICIENTS BOUNDS FOR CLASS OF ALMOST STARLIKE MAPPINGS OF ORDER $\alpha$ IN $\mathbb{C}^{n}$
}

\section{LIANGPENG XIONG}

Abstract. Let $\Omega$ be the bounded starlike circular domain. In this paper, we obtain the sharp bounds for the Fekete-Szegö functional $\left|A_{3}-\mu A_{2}^{2}\right|$ of the class $\mathscr{A}_{\alpha}^{*}(\Omega)$ of almost starlike mappings of order $\alpha$ in $\mathbb{C}^{n}(n \geqslant 2)$, where $\mu \in \mathbb{R}$, and $A_{2}, A_{3}$ are the first two coefficients of the homogeneous expansion of mappings $f \in \mathscr{A}_{\alpha}^{*}(\Omega)$. Our results can be regarded as the extensions of corresponding works from the case in one dimension to the case in higher dimensions.

Mathematics subject classification (2010): 32H02, 30C45.

Keywords and phrases: Almost starlike mappings, bounded starlike circular domain, complex $n$ dimensional space, sharp coefficients estimates.

\section{REFERENCES}

[1] Y. Abu Muhanna, L. Li, And S. Ponnus amy, Extremal problems on the class of convex functions of order $-\frac{1}{2}$, Arch. Math. (Basel), 103(6) (2014), 461-471.

[2] B. Bhowmik, S. Ponnus Amy And K.-J. Wirths, On the Fekete and Szegö problem for concave univalent functions, J. Math. Anal. Appl. 373 (2011), 432-438.

[3] L. BIEBERBACH, Über die Koeffizienten der einigen Potenzreihen welche eine schlichte Abbildung des Einheitskreises vermitten, S. B. Preuss. Akad. Wiss, 1916.

[4] H.CARTAN, Sur la possibilité détendre aux fonctions de plusieurs variables complexes la théorie des fonctions univalentes, in: Montel P. (Ed.), Lecons sur les Fonctions Univalentes ou Multivalentes, Gauthier-Villars, Paris, 1933.

[5] M. FeKetE, G. Szegö, Eine Bemerkunguber ungerade schlichte Funktionen, J. Lond. Math. Soc., 8, (1933), 85-89.

[6] I.Graham, G. Kohr, Geometric function theory in one and higher dimensions, Marcel Dekker, New York (2003).

[7] I.Graham, H.Hamada, T.Honda, K.H.Shon, Growth, distortion and coefficient bounds for Carathéodory families in $\mathbb{C}^{n}$ and complex Banach spaces, J. Math. Anal. Appl., 416, (2014), 449-469.

[8] S.Gong, The Bieberbach Conjecture, Amer. Math. Soc., International Press, Providence, RI, 1999.

[9] W. KoePF, On the Fekete-Szegö problem for close-to-convex functions II, Arch. Math. (Basel) 49(5) (1987), 420-433.

[10] S. KANAS, H. E. DARWISH, Fekete-Szegö problem for starlike and convex functions of complex order, Appl. Math. Lett., 23, (2010), 777-782.

[11] W.Koepf, On the Fekete-Szegö problem for close-to-convex functions, Proc. Amer. Math. Soc., 101, (1987), 89-95.

[12] L. Li, S. Ponnusamy AND J. Qiao, Generalized Zalcman conjecture for convex functions of order $\alpha$, Acta Mathematica Hungarica 150(1) (2016), 234-246.

[13] L. Li, S. Ponnusamy, On the generalized Zalcman functional $\lambda a_{n}^{2}-a_{2 n-1}$ in the close-to-convex family, Proc. Amer. Math. Soc., 145, (2017), 833-846.

[14] H.LuO, Q.H.Xu, On the Fekete and Szegö inequality for the subclass of strongly starlike mappings of order $\alpha$, Results Math., 72, (2017), 343-357.

[15] T.S.LIU, G.B.REN, The growth theorem for starlike mappings on the bounded starlike circular domain, Chin. Ann. Math., 19B, (1998), 401-408. 
[16] M.Obradović, S.Ponnus amy, K.J.Wirths, Coefficient characterizations and sections for some univalent functions, Sib. Math. J., 54(1), (2013), 679-696.

[17] H.ORHAN, E.DENIZ, D.RĂDUCANU, The Fekete-Szegö problem for subclasses of analytic functions defined by a differential operator related to conic domains, Comput. Math. Appl., 59, (2010), 283-295.

[18] H.ORHAN, E.DENIZ, M.ÇAĞLAR, The Fekete-Szegö problem for certain subclasses of analytic functions, Demonstratio Mathematica, XLV, (2012), 835-846.

[19] H. Orhan, E.ToKlu, E.KadioĞLu, Second Hankel determinant for certain subclasses of biunivalent functions involving Chebyshev polynomials, Turk. J. Math., 42, (2018), 1927-1940.

[20] C.Pommerenke, Univalent Functions, in: Studia Mathematica Mathematische Lehrbucher, Vandenhoeck and Ruprecht, 1975.

[21] H.M.Srivastava, A.K.Mishra, P.Gochhayat, Certain subclasses of analytic and bi-univalent functions, Appl. Math. Lett., 23, (2010), 1188-1192.

[22] H.M.Srivastava, S. Gaboury, F.Ghanim, Initial coefficient estimates for some subclasses of $m$-Fold symmetric bi-univalent functions, Acta. Math. Sci., 36B, (2016), 863-871.

[23] L.P.XIONG, X.D.FENG, J.L.ZHANG, Fekete-szegö inequality for generalized subclasses of univalent functions, J. Math. Inequal., 8, (2014), 643-659.

[24] Q. H. XU, T. S. LIU, Biholomorphic mappings on bounded starlike circular domains, J. Math. Anal. Appl., 366, (2010), 153-163.

[25] Q. H. XU, J. YOU, Coefficient inequality for a subclass of biholomorphic mappings in several complex variables, Complex Var. Elliptic., 63, (2018), 1306-1321.

[26] Q. H. XU, T. S. LiU, On the Fekete and Szegö problem for the class of starlike mappings in several complex variables, Abstr. Appl. Anal., ID 807026, (2014), 1-6. 